\title{
A SIMPLIFIED METHOD FOR THE DETERMINATION OF VITAMIN A IN THE PRESENCE OF CAROTENE IN ANIMAL TISSUES
}

\author{
KEIJI HARASHIMA, HISAYOSHI OKAZAKI ${ }^{1}$, AND HATSUO AOKI ${ }^{2}$ \\ Department of Agricultural Chemistry, Faculty of Agriculture, University \\ of Tokyo, Bunkyo-ku, Hongo, Tokyo \\ (Received January 30, 1961)
}

There are many methods for colorimetric determination of vitamin A in biological materials. None of them, however, is satisfactory in simplicity, since in these methods evaporation of the solvents used for the extraction of vitamin $A$ is indispensable. The microchemical method, devised by Bessey et al. (1) for the determination of vitamin A and carotene in blood serum, is very simple and easy to be carried out, since the evaporation process is not necessary. However, this method can not always be applied to the determination of vitamin $A$ in other biological materials, since the possible interference can not be excluded by the decomposition of any other substance showing light absorption in the region of $325-330 \mathrm{~m} \mu$.

Recent development in the determination of vitamin A by its conversion to anhydrovitamin A with $p$-toluene sulfonic acid in a benzene solution (2) suggested that the method as such may be used for a simple determination of vitamin A in animal tissues, because the use of benzene (3) for the extraction of vitamin A enables us to subject the extract directly to the dehydration reaction. Since this method requires complete exclusion of moisture and ethanol from the reaction mixture and the addition of the dehydration reagent to a sample solution results in five times dilution of the latter, the application of this reaction to the simple and rapid determination of vitamin $A$ is very difficult.

Recently it was found out that the dehydration of vitamin A in a benzene solution can be carried out with alcoholic hydrochloric acid as well, prepared by mixing concentrated hydrochloric acid and ethanol. This reaction is very suitable for the rapid and simple determination of vitamin A in biological materials, because complete exclusion of moisture is not necessary and the dehydration reagent can be removed very easily without the resulting dilution of the test solution by washing the reaction mixture with aqueous $\mathrm{NaOH}$. This paper deals with the details of the reaction and its application to the simple and rapid determination of vitamin $A$ in animal tissues.

1 Present address: Takeda Pharmaceutical Industries, Ltd., Osaka.

2 Present address: Tokyo Research Laboratory, Fujisawa Pharmaceutical Industries, Ltd., Tokyo. 


\section{EXPERIMENTAL}

\section{Reagents and Materials}

Ethanol-99\% ethanol was distilled over zinc added with $\mathrm{KOH}(4) . \quad 98-$ $99 \%$ ethanol thus obtained was used throughout the experiment.

$1 \%$ Hydroquinone in Ethanol - $2 \mathrm{~g}$ of hydroquinone ("extra pure" grade) was dissolved in $200 \mathrm{ml}$ of ethanol. This reagent keeps for about 3 weeks in the cold.

Ethanolic Hydrochloric Acid Ten volumes of ethanol was added to one volume of concentrated hydrochloric acid (35\%). The mixture was shaken vigorously until the evolution of heat came to a halt. The reagent keeps for at least one week at room temperature.

Benzene - Benzene of guaranteed reagent grade was washed successively with concentrated $\mathrm{H}_{2} \mathrm{SO}_{4}$, aqueous $5-10 \% \mathrm{NaOH}$ and water and distilled after being dried over anhydrous $\mathrm{CaCl}_{2}$.

Solution of Vitamin A Alcohol in Benzene Crystalline vitamin A acetate, generously supplied by the Riken Vitamin Co., or vitamin A standard oil, purchased from the National Institute of Health, was saponified with $1 \mathrm{~N}$ $\mathrm{KOH}$ in ethanol under a stream of $\mathrm{N}_{2}$ and vitamin $\mathrm{A}$ alcohol liberated was extracted with ethyl ether in a similar manner as described in the U.S. Pharmacopaeia XV (5). Vitamin A alcohol thus extracted was dissolved in benzene after evaporation of ethyl ether.

Vitamin A Standard Solution-A solution of vitamin A, prepared from the vitamin A standard oil, was used as a standard solution after the determination of vitamin A concentration by the ultraviolet-irradiation method (6) with some modifications. The apparatus used for the irradiation was that already reported for the microchemical determination of vitamin $A$ in blood serum (7). $\quad 5 \mathrm{ml}$ of the standard solution was placed in a glass-stoppered test tube $(12 \times 70 \mathrm{~mm})$ at a distance of $5 \mathrm{~cm}$ from the center of the lamp. Irradiation for 150 minutes was satisfactory for the complete destruction of vitamin A. Cooling the test solution with a fan was omitted. $E_{331}{ }^{3}$ was measured before and after the irradiation. Vitamin A concentration was calculated from the difference of $E_{1}^{1 \%} \mathrm{~cm}$ before and after the irradiation, which was determined to be $1590\left( \pm 40^{4}\right)$ by using a solution of crystalline vitamin A alcohol (kindly presented by the Sumitomo Kagaku Co.) or a vitamin A solution prepared from crystalline vitamin A acetate.

\section{Procedures}

Extraction of Vitamin A (and Carotene) from the Homogenate of Animal Tissue-Digestion of tissues was made by an ordinary method (3). $5 \mathrm{ml}$ homogenate of the liver or intestinal wall of a rat was placed in a glass-

${ }^{3}$ Light absorbancy is represented by $E$ with a suffix representing the wavelength in $\mathrm{m} \mu$ at which the measurement was made, and difference of light absorbancies is expressed by $\Delta E$ (light path, $1 \mathrm{~cm}$ ).

4 Standard deviation. 
stoppered centrifuge tube of $25 \mathrm{ml}$ capacity, $1 \mathrm{ml}$ of water, $6 \mathrm{ml}$ of $1 \%$ hydroquinone in ethanol and $0.6 \mathrm{ml}$ of aqueous $50 \% \mathrm{KOH}$ were added. The mixture was incubated for 30 minutes at $70-75^{\circ}$ (bath temperature) and then cooled to room temperature as soon as possible. Then $6 \mathrm{ml}$ of benzene was added to the mixture, which was vigorously shaken for 30-60 seconds and centrifuged for 5-10 minutes at 2000 r.p.m. A clear benzene solution thus separated was transferred to another test tube and was shaken with $6 \mathrm{ml}$ of water. Sometimes an emulsion was formed at this stage. Addition of a small amount of anhydrous $\mathrm{Na}_{2} \mathrm{SO}_{4}$ and centrifugation of the benzene solution removed the emulsion completely. The benzene extract thus obtained was dried over anhydrous $\mathrm{Na}_{2} \mathrm{SO}_{4}$.

Determination of Vitamin $A$ and Carotene in the Extract Concentration of carotene was determined by measuring $E_{465}$ and that of vitamin $\mathrm{A}$ by the dehydration reaction. $4.5 \mathrm{ml}$ of the alcoholic hydrochloric acid was placed in an umber-colored test tube with a glass stopper and kept at $15^{\circ} .4 .5 \mathrm{ml}$ of the extract was pipetted into the test tube and mixed well with the reagent. After 15 minutes, $4.5 \mathrm{ml}$ of aqueous $1.5 \mathrm{~N} \mathrm{NaOH}$ was added and the test tube was vigorously shaken for a while. The mixture was allowed to stand until the benzene layer separated, which was transferred to another test tube and washed with $4.5 \mathrm{ml}$ of distilled water. The benzene solution thus obtained was dried over a small amount of anhydrous $\mathrm{Na}_{2} \mathrm{SO}_{4}$ to eliminate turbidity. $E_{377}$ was measured before and after the reaction. The dehydration reaction was carried out also with the standard solution.

Calculation The amount of vitamin A contained in the homogenate was calculated by the following formula.

$$
A=c_{0} \times \begin{aligned}
& E_{2,1} / 1.05-E_{1,1} \\
& E_{2,0} / 1.05-E_{1,0}
\end{aligned} \times \frac{6}{1.06} \quad(\mu \mathrm{g})
$$

where $A$ is the amount of vitamin $\mathrm{A}$ in the homogenate, $c_{o}$ the concentration of vitamin $A$ in the standard solution $(\mu \mathrm{g} / \mathrm{ml}), E_{1,0}$ and $E_{1,1}$ are $E_{337}$ of the standard solution and the extract, respectively, before the reaction, and $E_{\mathbf{2}, 0}$ and $E_{2,1}$ are $E_{337}$ of those after the reaction.

The amount of $\beta$-carotene was calculated by the following formula:

$$
B=\left(E_{465} / 2337\right) \times 10^{4} \times 6 / 1.06(\mu \mathrm{g})
$$

where $B$ is the amount of $\beta$-carotene, and 2337 is the extinction coefficient of $\beta$-carotene in benzene (8).

\section{RESULTS}

\section{Correction for the Loss of Benzene}

A small amount of benzene was lost in the course of the dehydration reaction or of the extraction process, owing partially to the inclusion of benzene in the aqueous alcoholic layer and partially to evaporation. In order to estimate the amount of benzene lost, the change in $E_{465}$ of a carotene solution or in $E_{331}$ of a vitamin A solution was measured during the treatment of the solution with a $1: 1$ mixture of ethanolic hydrochloric acid and aqueous 
TABLE I

Increase in Absorbancy of a Benzene Solution of Carotene or Vitamin A Caused by Loss of Bensene on Treatment with Aqueous Alkaline Ethanol

Experiment

no.
$E_{1}{ }^{a}$

0.400

0.848

0.326

0.161

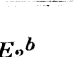

$E_{2}{ }^{b}$

0.423

0.879

0.342

$-$

\begin{tabular}{cc}
$E_{3}{ }^{c}$ & $E_{3} / E_{\mathbf{1}}$ \\
\hline 0.427 & 1.068 \\
0.889 & 1.048 \\
0.346 & 1.061 \\
0.172 & 1.069
\end{tabular}

1.06

In Experiments 1 and 2, benzene solutions of $\beta$-carotene were employed and $E_{465}$ were measured before and after the treatment with aqueous alcoholic alkali, and in Experiments 3 and 4, solutions of vitamin $A$ were employed and $E_{331}$ were measured.

${ }^{a} E$ initially observed.

$b E$ observed after treating $5 \mathrm{ml}$ of the sample solution with a mixture of $5 \mathrm{ml}$ of the alcoholic hydrochloric acid and $5 \mathrm{ml}$ of aqueous $1.5 \mathrm{~N} \mathrm{NaOH}$.

${ }^{c} E$ observed after treating $5 \mathrm{ml}$ of the sample solution with a mixture of $5 \mathrm{ml}$ of ethanol, $0.5 \mathrm{ml}$ of aqueous $50 \% \mathrm{KOH}$ and $5 \mathrm{ml}$ of water.

$1.5 \mathrm{~N} \mathrm{NaOH}$ or with a mixture of ethanol, aqueous $50 \% \mathrm{KOH}$ and water. Table I shows the results of this experiment. The observed increase in $E$ of the carotene solution or of the vitamin A solution must be caused by the reduction of the volume of the solution during the treatment. The mean value of $E_{2} / E_{1}(1.05)$ was used for calculating the change in the volume of the test solution during the dehydration reaction, and the mean value of $E_{3} / E_{1}$ (1.06) was used for calculating the change in the volume of benzene during the extraction process. This is the meaning of the figures in the formulae $a$ and $b$, and $E$ after the dehydration reaction was divided by 1.05 throughout the experiment.

2. Change in the Absorption Spectrum of Vitamin A Caused by the Dehydration Reaction

Absorption spectra of vitamin A before and after the dehydration reaction are shown in Fig. 1. Three absorption maxima characteristic of anhydrovitamin A were observed after the reaction. Although the position of the maxima (357, 377 and $399 \mathrm{~m} \mu$ ) were consistent with those reported by Budowsky and Bondi (2), relative intensities of light absorption at these wavelengths were different from those reported by them and the yield of anhydrovitamin A seemed to be lower than that obtained with $p$-toluene sulfonic acid. However, as described in a later section, the differences of the absorbancies before and after the reaction $(\Delta E)$ at these wavelengths were proportional to the vitamin A concentrations. Therefore, vitamin A could be determined by this reaction.

\section{Reaction Temperature and $\mathrm{HCl}$ Concentration}

Fig. 2 shows the effect of temperature on the dehydration reaction. Maximum absorbancies obtained were almost the same for all the reaction tem- 


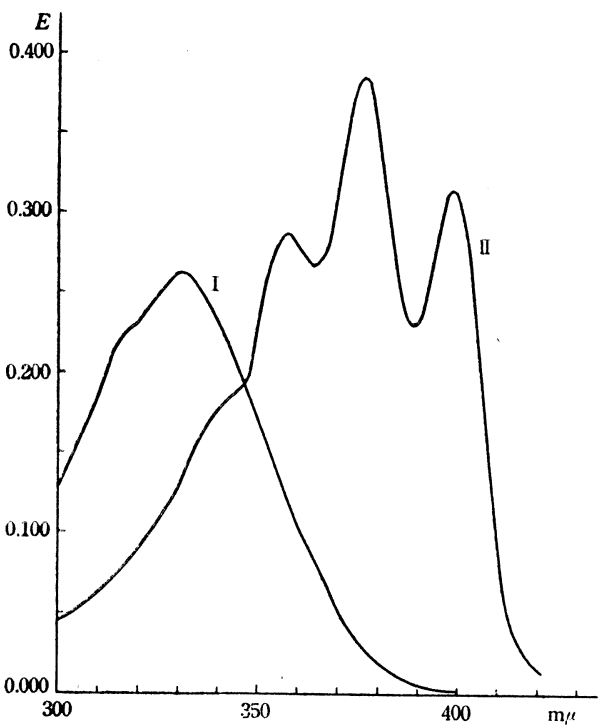

Fig. 1 Change in Absorption Spectrum of Vitamin $A$ by the Dehydration Reaction I, before dehydration; II, after dehydration

$0.0599 \mathrm{~g}$ of vitamin A acetate $\left(E_{1}^{1 \%} \mathrm{~cm}=1529\right.$ in ethanol) was dissolved in $50 \mathrm{ml}$ of ethanol. $1 \mathrm{ml}$ of this solution was submitted to saponification and extraction with ethyl ether. The unsaponifiable matter thus obtained was dissolved in $625 \mathrm{ml}$ of benzene. This solution was submitted to dehydration.

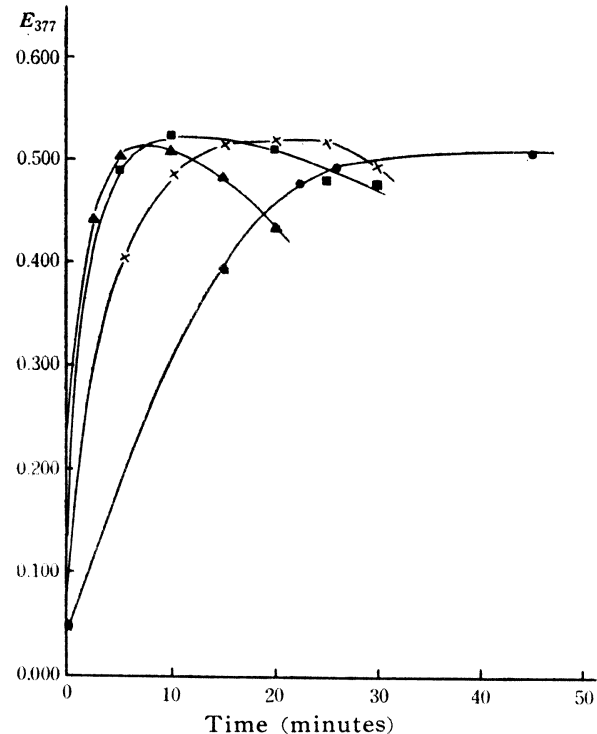

Fis. 2 Courses of Dehydration at Various Reaction Temperatures

-, reaction at $10^{\circ} ; \times$ reaction at $15^{\circ}$; $\mathbf{\square}$, reaction at $20^{\circ} ; \boldsymbol{\Delta}$, reaction at $25^{\circ}$. Unsaponifiable matter from $0.178 \mathrm{~g}$ of vitamin A standard oil was dissolved in 250 $\mathrm{ml}$ of benzene and submitted to dehydration (initial value of $E_{331}$ being 0.349 ).

perature tested. However, when a 1:10 mixture of ethanol and $\mathrm{HCl}$ was used as the dehydration reagent, the reaction temperature $15^{\circ}$ and $20^{\circ}$ were the most suitable. The reaction velocity was too high at $25^{\circ}$, while too low at $10^{\circ}$. At $15^{\circ}$ the absorbancy reached the maximum value $15-20$ minutes after mixing the test solution with the reagent, and remained unchanged for 5-10 minutes. A lowered concentration of $\mathrm{HCl}$ caused a decrease in the reaction velocity, enabling us to carry out the reaction at a higher temperature. When a 1:40 mixture of $\mathrm{HCl}$ and ethanol was used as the reagent, the reaction velocity at $25^{\circ}$ was comparable to that obtained with the $1: 10$ mixture at $15^{\circ}$ (see also Fig. 3). For convenience, the dehydration reaction was carried out at the proposed condition throughout the experiments in this paper.

\section{Linear Relationship between $\Delta E$ and Vitamin $A$ Concentration}

In Fig. 3 the values of $\Delta E$ at 377 and $399 \mathrm{~m} \mu$ are plotted against the concentrations of vitamin A. Linear relationships were obtained. The slopes of the straight lines, showing the increase in absorbancies per unit amount of vitamin A, differed a little from experiment to experiment. Therefore the 


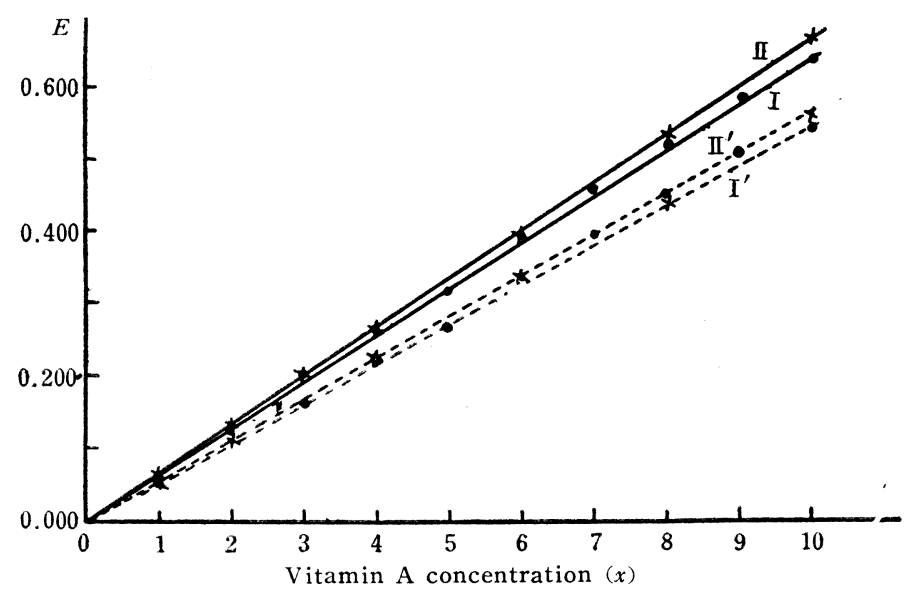

Fic. 3 Relationship between the Increase in $E$ and the Concentration of Vitamin $A$ I, I': Reaction at $15^{\circ}$ for 15 minutes with $1: 10$ mixture of $\mathrm{HCl}$ and ethanol.

II, $\mathrm{II}^{\prime}$ : Reaction at $25^{\circ}$ for 15 minutes with $1: 40$ mixture of $\mathrm{HCl}$ and ethanol.

I, II : Increase in $E_{377} ; \mathrm{I}^{\prime}, \mathrm{II}^{\prime}$ : Increase in $E_{399}$

Line I : $\Delta E=0.003+0.0649 x\left(s^{a}=0.008\right)$, Line II : $\Delta E=-0.002+0.0673 x\left(s^{a}=0.004\right)$

Line $\mathrm{I}^{\prime}: \Delta E=-0.002+0.0560 x\left(s^{\boldsymbol{a}}=0.006\right)$, Line $\mathrm{II}^{\prime}: \Delta E=-0.004+0.0571 x\left(s^{\boldsymbol{a}}=0.002\right)$

Unsaponifiable matter from $0.276 \mathrm{~g}$ of vitamin A standard oil was dissolved in $250 \mathrm{ml}$ of benzene. Vitamin A concentration is expressed by the volume (ml) of this solution $^{b}$ contained in each $10 \mathrm{ml}$ of the test solution.

a Standard deviation of $\triangle E$ measured around the straight line.

$b$ Vitamin A concentration in this solution was determined to be $2.98 \mu \mathrm{g} / \mathrm{ml}$ by the ultraviolet-irradiation method.

use of the standard solution of vitamin A was required for an accurate determination. The mean value of $\Delta E_{1 \mathrm{~cm}}^{1 \mathrm{~m}^{5}}$ at $377 \mathrm{~m} \mu$ obtained by six experiments was $2.21\left( \pm 0.04^{6}\right)$. As shown in Fig. 3, the $\Delta E$ at $399 \mathrm{~m} \mu$ was also proportional to the concentration of vitamin A. However, the determination of vitamin $\mathrm{A}$ was made by measuring the $E_{337}$ before and after the reaction, because the $\Delta E$ at $377 \mathrm{~m} \mu$ was greater than that at $399 \mathrm{~m} \mu$.

\section{Determination of Vitamin $A$ in the Extract from Rat Liver Homogenate}

Fig. 4 shows the difference spectra of the unsaponifiable matter from rat liver homogenate and of authentic vitamin A. The difference spectrum of the rat liver extract was fairly consistent with that of vitamin A. Therefore, the availability of the dehydration reaction for the determination of vitamin $A$ in liver homogenate seemed to be supported. The extract from intestinal wall contained scarcely any vitamin A. Hence, the difference spectrum of the extract from intestinal wall could not be obtained.

\section{Reaction of $\beta$-Carotene with Alcoholic Hydrochloric Acid}

It is often necessary to determine vitamin $A$ in the presence of a large

${ }^{5}$ In this paper, the increase in $E$ (measured by using a cuvette with a light path of $1 \mathrm{~cm}$ ) given by a solution, containing $1 \mathrm{mg}$ of vitamin $\mathrm{A}$ per $100 \mathrm{ml}$, is expressed by $\Delta E_{1 \mathrm{~cm}}^{1 \mathrm{mg}}$.

${ }^{6}$ Standard deviation. 


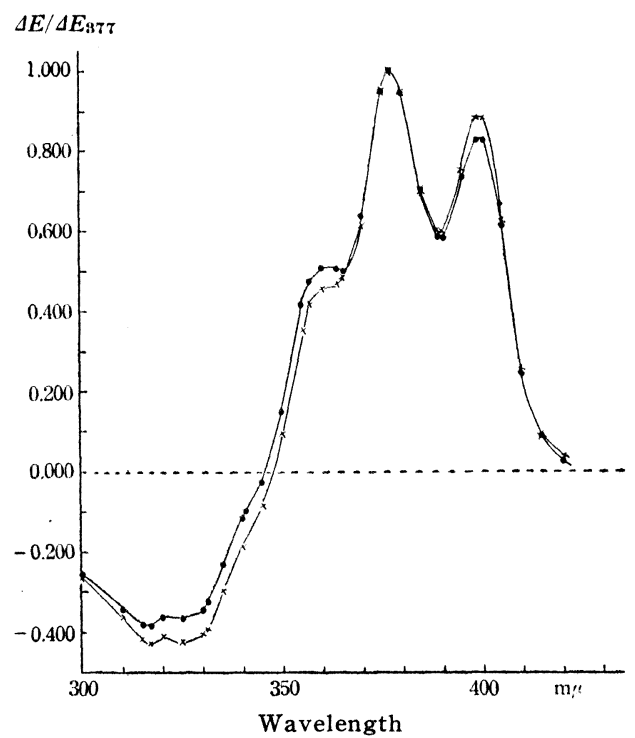

FIr. 4 Difference Spectrum of the Unsaponifiable Matter from Rat Liver

Relative value of $\Delta E\left(\Delta E_{377}\right.$ being taken as 1.000$)$ is plotted against wavelength.

- unsaponifiable matter from a crystalline vitamin A acetate. (Vitamin A concentration, $24.1 \mu \mathrm{g} / \mathrm{ml}) . \quad \Delta E_{377}=0.590$

, unsaponifiable matter from rat liver. $\quad(2 \mathrm{~g}$ of rat liver was digested with $10 \mathrm{ml}$ of ethanol, containing $0.1 \mathrm{~g}$ of hydroquinone, and $1 \mathrm{ml}$ of $50 \%$ aqueous $\mathrm{KOH}$ for 30 minutes at $70-75^{\circ}$, extracted with $10 \mathrm{ml}$ of benzene, and the benzene solution was washed with $10 \mathrm{ml}$ of water and diluted 5 fold. The solution was submitted to the dehydration reaction. $\Delta E_{377}=1.02$

amount of $\beta$-carotene. Therefore, the change in $E_{377}$ of $\beta$-carotene in benzene, caused by the treatment with alcoholic hydrochloric acid was also investigated (Table II). The increase in $E_{377}$ due to $\beta$-carotene was very small. Presence

TABLE II

Reaction of $\beta$-Carotene with Alcoholic Hydrochloric Acid

\begin{tabular}{cccccc}
\hline $\begin{array}{c}\text { Concentration } \\
\text { of } \beta \text {-carotene }\end{array}$ & $\Delta E_{\mathbf{3 3 1}}$ & $\Delta E_{\mathbf{3 5 7}}$ & $\Delta E_{\mathbf{8 7 7}}$ & $\Delta E_{\mathbf{3 9 9}}$ & $\Delta E_{\mathbf{4 6 5}}$ \\
\hline$\mu g / m l$ & & & & & \\
0.94 & 0.017 & 0.015 & 0.006 & 0.006 & 0.224 \\
1.88 & 0.023 & 0.021 & 0.008 & 0.003 & 0.443 \\
4.70 & 0.025 & 0.025 & 0.006 & 0.005 & 1.07 \\
9.40 & 0.023 & 0.021 & 0.003 & 0.004 & - \\
\hline
\end{tabular}

$5 \mathrm{ml}$ of a solution of $\beta$-carotene was treated with a $10: 1$ mixture of ethanol and concentrated hydrochloric acid in the same manner as that for the determination of vitamin A. Increases in the absorbancies were measured.

of $\beta$-carotene in the test solution may, therefore, give only very little effect on the determined value of vitamin A. Actually, as seen in Table III, determination of vitamin $A$ in the presence of various amounts of $\beta$-carotene 
TABLE III

Determination of Vitamin $A$ in the Presence of $\beta$-Carotene

\begin{tabular}{cccc}
\hline \multicolumn{2}{c}{ Concentration of } & $\begin{array}{c}\text { Determined values } \\
\text { of vitamin A }\end{array}$ & $\begin{array}{c}\text { Differences of the } \\
\text { determined and the } \\
\text { theoretical values }\end{array}$ \\
\hline$\mu g / m l$ & Vitamin A & $\mu g / m l$ & $\mu g / m l$ \\
1.19 & $\mu g / m l$ & 1.12 & 0.02 \\
3.81 & 1.10 & 0.46 & 0.02 \\
3.81 & 0.44 & 0.93 & 0.03 \\
3.81 & 0.90 & 0.03 & 0.03 \\
1.54 & - & 0.04 & 0.04 \\
\hline
\end{tabular}

Each $5 \mathrm{ml}$ of solutions containing various amounts of vitamin $A$ and $\beta$-carotene was treated with the dehydration reagent. In this case, unsaponifiable matter from natural vitamin A palmitate dissolved in soy bean oil ${ }^{a}$ (nominally containing $1,000,000$ I. U. of vitamin $\mathrm{A} / \mathrm{g}$ of oil) was used as vitamin $\mathrm{A}$.

a The preparation of natural vitamin A palmitate was kindly presented by the Kawai Seiyaku Co., to whom the authors wish to express their cordial thanks.

by the dehydration reaction gave values nearly consistent with, but slightly higher than, the theoretical values. Differences of the observed and the theoretical values were in the range of $0.02-0.04 \mu \mathrm{g} / \mathrm{ml}$. There was no correlation between the amount of $\beta$-carotene $(0.4-3.8 \mu \mathrm{g} / \mathrm{ml})$ and the increase in the observed value of vitamin A. It seems, therefore, reasonable that 0.03 $\mu \mathrm{g} / \mathrm{ml}$ is to be subtracted from the determined value of vitamin $A$, when the test solution contains $0.4-3.8 \mu \mathrm{g} / \mathrm{ml}$ of $\beta$-carotene. Probably even a larger amount of $\beta$-carotene (3.8-9.4 $\mu \mathrm{g} / \mathrm{ml})$ would not cause a significant inter-

TABLE IV

Recoveries of $\beta$-Carotene, with or without Hydroquinone, Added to the Digestion Mixture

\begin{tabular}{lcccc} 
Tissue & Hydroquinone & $\begin{array}{l}\text { Amount of } \beta \text { - } \\
\text { carotene added }\end{array}$ & $\begin{array}{l}\text { Amount of } \beta \text {-ca- } \\
\text { rotene recovered }\end{array}$ & $\begin{array}{l}\text { Percentage } \\
\text { recovered } \boldsymbol{a}\end{array}$ \\
& & $\mu g$ & $\mu g$ & $\%$ \\
Intestinal & & 4.74 & 4.08 & 86.1 \\
wall & 9.47 & 7.73 & 81.8 \\
& - & 18.94 & 15.73 & 83.2 \\
& - & 8.08 & 7.45 & 92.2 \\
\hline Liver & - & 15.10 & 12.82 & 84.9 \\
& - & 15.10 & 14.90 & 98.7 \\
& + & 22.90 & 21.90 & 95.6 \\
& + & 17.09 & 16.90 & 98.8 \\
\hline
\end{tabular}

Rat liver or intestinal wall was homogenized with an equal volume of KrebsRinger-phosphate solution. $1 \mathrm{ml}$ of the homogenate was suspended in $4 \mathrm{ml}$ of KrebsRinger-phosphate solution. The suspension thus obtained was subjected to the determination.

For the addition of $\beta$-carotene, a part of water added to the homogenate (suspension) was replaced by a water dispersion of $\beta$-carotene.

${ }^{a}$ Difference between the determined values of $\beta$-carotene in tissue homogenate with and without added $\beta$-carotene. 
ference with the determination of vitamin A by this reaction (see Table II).

\section{Recovery Tests}

The proposed method for the digestion of tissue homogenate and the extraction of vitamin A and carotene is essentially similar to that in the method proposed by Fujita et al. (3). However, since in the proposed method extraction of vitamin $A$ is not repeated, the recovery tests were undertaken. Vitamin $\mathrm{A}$ and $\beta$-carotene were added as water suspensions to the homogenates prior to the digestion with alkali and the amounts recovered in the

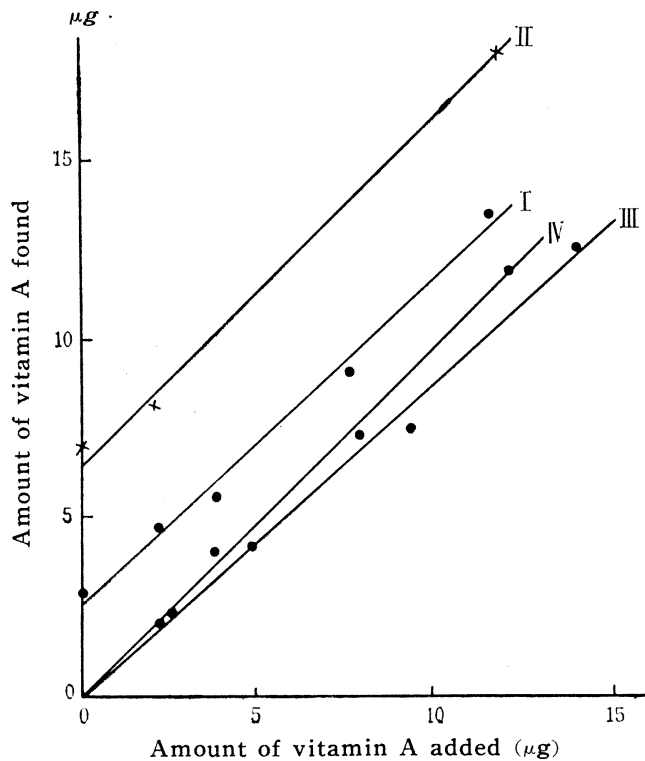

FIt. 5 Recoveries of Vitamin it

I, $Y=2.30+0.93 x\left(s=0.31^{a}, s_{\mathrm{b}}=0.034^{b}\right)$ (liver without adding $\beta$-carotene) $4.5 \mathrm{~g}$ of rat liver was well washed with Krebs-Ringer-phosphate solution and homogenized with an equal volume of the same solution. One $\mathrm{ml}$ of this homogenate was suspended in $3.4 \mathrm{ml}$ of Krebs-Ringer-phosphate solution with addition of $1.6 \mathrm{ml}$ of water and subjected to the determination of vitamin A. A part of this water was replaced by the water suspension of vitamin $A$.

II, $Y=6.28+0.99 x\left(s=0.62^{a}, s_{\mathrm{b}}=0.065^{b}\right)$ (liver, $\beta$-carotene being added). Preparation of rat liver homogenate and suspension were made in the same manner as described above. $0.5 \mathrm{ml}$ of water added was replaced by $0.5 \mathrm{ml}$ of the water suspension of $\beta$ carotene $(25.8 \mu \mathrm{g})$.

III, $Y=0.04+0.88 x\left(s=0.28^{a}, s_{\mathrm{b}}=0.025^{b}\right)$ (intestinal wall without adding $\beta$-carotene) $9 \mathrm{~g}$ of rat intestinal wall was well washed with Krebs-Ringer-phosphate solution and homogenized with $9 \mathrm{ml}$ of the same solution. $4 \mathrm{ml}$ of this homogenate was submitted to the determination of vitamin $A$ with or without addition of vitamin A.

IV, $Y=0.08+0.99 \times\left(s=0.17^{a}, s_{\mathrm{b}}=0.018^{b}\right)$ (intestinal wall, $\beta$-carotene being added) $9 \mathrm{~g}$ of rat intestinal wall were well washed and homogenized with $4.5 \mathrm{ml}$ of KrebsRinger phosphate solution. $1 \mathrm{ml}$ of this homogenate was suspended and subjected to the determination of vitamin $A$ as described above, with addition of the water suspension of $\beta$-carotene $(22.1 \mu \mathrm{g})$.

${ }^{a}$ Standard deviation of the determined values of vitamin $A$ around the straight line

$b$ Standard deviation of the slope of the straight line calculated from $s$. 
extracts were determined. Fig. 5 shows the recoveries of vitamin $A$ in the presence and in the absence of added $\beta$-carotene. The straight lines in this figure are drawn by the method of least squares. The slopes of these straight lines indicate the ratios of the amounts of vitamin A recovered to the amounts added. The ratios were in the range of $0.88-0.99$. Table IV shows the recoveries of carotene. The ratios of the recoveries were in the range of $0.92-0.99$. A small part of vitamin A or carotene was lost in the course of extraction. It may be considered that the loss of vitamin $A$ or of $\beta$-carotene might have been due to incomplete extraction. However, Table $\mathrm{V}$ indicates that the amounts of vitamin $\mathrm{A}$ and $\beta$-carotene remaining unextracted after the extraction with the first $6 \mathrm{ml}$ of benzene were less than about $3 \%$ and the loss described above could not be explained by the incomplete extraction. Since the first extract could not be completely removed from the centrifuge tube before the addition of the second $6 \mathrm{ml}$ of benzene, presence of vitamin $A$ and $\beta$-carotene in the second extract was considered to be largely due to the contamination of a small amount of the first extract. Hence the loss of vitamin $\mathrm{A}$ and carotene seemed to be due to the oxidation during the digestion of tissue with alkali, and the repeated extraction seemed unneccessary.

TaBLE V

Amounts of Vitamin $A$ and $\beta$-Carotene Remaining Unextracted in the Digestion Mixture after the First Extraction with Benzene

\begin{tabular}{|c|c|c|c|c|c|c|}
\hline & \multicolumn{2}{|c|}{$\begin{array}{l}\text { Amount in the } \\
\text { first extract }\end{array}$} & \multicolumn{2}{|c|}{$\begin{array}{l}\text { Amount in the } \\
\text { second extract }\end{array}$} & \multicolumn{2}{|c|}{$\begin{array}{l}\text { Percentage of } \\
\text { remaining }\end{array}$} \\
\hline & Vitamin A & $\beta$-Carotene & Vitamin A & $\beta$-Carotene & $\overline{\text { Vitamin } A}$ & $\beta$-Carotene \\
\hline & $" g$ & $\mu g$ & $\mu g$ & $\mu g$ & $\%$ & $\%$ \\
\hline Liver 1 & 7.63 & $54.1^{a}$ & 0.19 & 1.72 & 2.5 & 3.2 \\
\hline Liver 2 & $\left\{\begin{array}{l}345 \\
338\end{array}\right.$ & $\overline{59.4^{b}}$ & $\begin{array}{l}7.1 \\
5.9\end{array}$ & $\overline{0.51}$ & $\begin{array}{l}2.0 \\
1.7\end{array}$ & $\overline{0.9}$ \\
\hline $\begin{array}{l}\text { Carotene } \\
\text { water dispersion }\end{array}$ & & 62.0 & - & 0.15 & - & 0.2 \\
\hline
\end{tabular}

After the first benzene extraction, the extract was transferred to another test tube, the second $6 \mathrm{ml}$ of benzene was added to the aqueous alcoholic layer remaining in the centrifuge tube, and the mixture was vigorously shaken. The benzene layer separated after centrifugation was washed with water and submitted to the measurement of vitamin A or carotene concentration. Correction of the volume of benzene was omitted since the aqueous alcoholic layer contains a little benzene and its loss is considered to be very small. Other experimental conditions were similar to those proposed.

a $55.8 \mu \mathrm{g}$ of $\beta$-carotene was added to the homogenate.

${ }^{b} 62.0 \mu \mathrm{g}$ of $\beta$-carotene was added to the homogenate.

\section{Requirement of Hydroquinone}

Table IV also demonstrates the requirement of adding hydroquinone to the digestion mixture for the determination of carotene. In the absence of hydroquinone, recoveries of added $\beta$-carotene were very poor. On the contrary, elimination of hydroquinone from the digestion mixture showed almost no 
effect on the recoveries of vitamin A. However, since the addition of hydroquinone did not show any interference with the determination of vitamin A, hydroquinone was added to the digestion mixture even when the concomitant determination of $\beta$-carotene is not included. The amount of hydroquinone required was $1 \%$ of the volume of ethanol employed.

\section{Semimicro Determination}

By application of a micro cuvette and diaphragms devised by Lowry and Bessey (9), semimicro determination of vitamin $A$ and $\beta$-carotene is possible by the proposed method. For convenience of measuring absorbancies, the cuvette and the diaphragm were modified. A cuvette with a inner dimen-

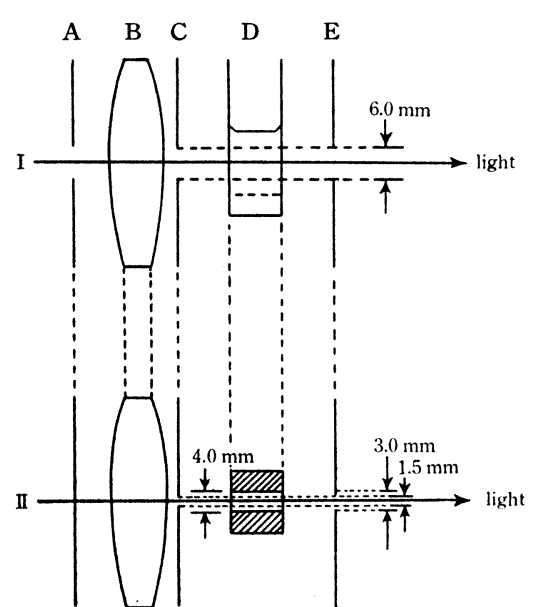

Fig. 6 Arrangements of Diaphragms and Cuvette for the Semimicro Measurement of Light Absorption

I: side view; II: plane figure

A, slit for adjusting the volume of light;

B, lens ; C, diaphragm I ; D, cuvette ; E, diaphragm II. sion of $4 \times 10 \mathrm{~mm}$ was used and the volume of the sample solution used for the measurement of absorbancies were $0.6 \mathrm{ml}$. When a Hitachi spectrophotometer (Model EPU-2A) was used, the width of the cuvette could not be minimized to less than $4 \mathrm{~mm}$, and a second diaphragm placed after the cuvette ensured an accurate determination of absorbancies, because the width of light beam was less than $4 \mathrm{~mm}$. In Fig. 6 the arrangements of the diaphragms with rectangular holes are schematically illustrated. In the semimicro method, $1 \mathrm{ml}$ of the tissue homogenate was digested with $1 \mathrm{ml}$ of ethanol containing $1 \%$ hydroquinone and 0.1 $\mathrm{ml}$ of aqueous $50 \% \mathrm{KOH}$, and vitamin $A$ and carotene were extracted with $1 \mathrm{ml}$ of benzene. Small centrifuge

TABLE VI

Comparison of the Values of Vitamin A Determined by the Semimicro and Macro Method

\begin{tabular}{lc}
\hline \hline Method & Concentration of vitamin A \\
\hline & $\mu g / m l$ \\
Macro & $29.1 \pm 0.1$ \\
Semimicro & $28.5 \pm 0.1$
\end{tabular}

The values represent the amount of vitamin $\mathrm{A}$ (in $\mu \mathrm{g}$ ) contained in $1 \mathrm{ml}$ of rat liver homogenate, which was obtained by homogenizing rat liver with an equal volume of Krebs-Ringer-phosphate solution (average of duplicate determinations). 1 $\mathrm{ml}$ of the homogenate was suspended in $4 \mathrm{ml}$ of Krebs-Ringer-phosphate solution in the macro method, and $0.2 \mathrm{ml}$ of the homogenate was suspended in $0.8 \mathrm{ml}$ of KrebsRinger-phosphate solution in the semimicro method before digestion with alkali. 
tubes and small test tubes were used. The dehydration reaction was performed by mixing $0.8 \mathrm{ml}$ of the extract with $0.8 \mathrm{ml}$ of the reagent. The width of light wavelength was less than $1 \mathrm{~m} \mu$. In Table VI the result is given of an example of the semimicro determination of vitamin $A$ in rat liver homogenate. The value obtained by the semimicro method is fairly consistent with that by the macro method.

\section{DISCUSSION}

The reagent for dehydration of vitamin A, originally used by Edisbury et al. (10), was a moisture-free alcoholic hydrogen chloride, which was prepared by introducing dry hydrogen chloride into absolute ethanol. The reagent used in the proposed method, however, is alcoholic hydrochloric acid, which was prepared by mixing concentrated hydrochloric acid with ethanol. Thus the reagent itself contains a small amount of water, and special care for the exclusion of moisture is not required. Moreover, the dehydration reaction was carried out in a benzene solution, as in the case of Budowsky and Bondi's method (2). Dilution of the sample solution with the reagent did not occur. Therefore, the dehydration procedure used in the proposed method is very suitable for the rapid and simple determination of vitamin A. Presence of $\beta$-carotene in the test solution interfered with the determination only to a small extent. Esterified vitamin A did not react with the reagent. Therefore, saponification of vitamin A ester is a prerequisite in the proposed method.

Recovery of vitamin $A$ or of $\beta$-carotene added to the homogenate was not 100\%. However, the difference of the recoveries of vitamin A added to the homogenate in the presence and in the absence of $\beta$-carotene is not significant, and the average of the recoveries found, $0.95( \pm 0.06)$, seems to be satisfactory for the ordinary use of biochemical researches.

The proposed method can be applied to the determination of vitamin A in the semimicro scale as shown in Table VI. The determination of vitamin $A$ in about 10 samples could be carried out in 6 hours by the semimicro method. Probably this method can be applied to the micro determination of vitamin A in blood serum in a smaller scale. Application of the proposed method to the determination of vitamin $A$ in other tissues awaits further investigations.

\section{SUMMARY}

A simplified method is proposed for the rapid determination of vitamin $\mathrm{A}$ in animal tissues in the presence of a large amount of $\beta$-carotene, using a modified method for dehydration of vitamin A. Special care for the exclusion of moisture was not required, since the dehydration reagent used was alcoholic hydrochloric acid containing a small amount of water. Evaporation process was not needed, because the dehydration reaction was carried out in a benzene solution and the sample solution was not diluted with the reagent. 
Single extraction with benzene was enough to extract vitamin $A$ and $\beta$-carotene almost completely from the digested homogenate. The recoveries of vitamin $\mathrm{A}$ and $\beta$-carotene added to the tissue homogenates prior to the alkali digestion were satisfactory for ordinary biochemical researches. Application of this method to the semimicro determination of vitamin $\mathrm{A}$ is also presented. The determination of the amounts of vitamin $A$ and carotene in about 10 samples were possible in about 6 hours.

\section{ACKNOWLEDGEMENT}

The authors wish to express their appreciation to Prof. S. Funahashi for his advice and encouragement throughout this work, to Prof. M. Matsui and Mr. S. Okano (The Sumitomo Kagaku Co.) for their generous gift of crystalline preparations of vitamin $\mathrm{A}$ alcohol and to Mr. T. Kitagawa (The Riken Vitamin Co.) for his generous gift of crystalline preparations of vitamin A acetate. The authors are also grateful to the Ministry of Education for a grant in aid.

\section{REFERENCES}

1. Bessey, O.A., Lowry; O.H., Brock, M.J., and Lopetz, J.A., J. Biol. Chem. 166, 177 (1946).

2. Budowsky, P., and Bondi, A., Analyst 82, 751 (1957).

3. Fujita, A., Method of Vitamin Assay (Japanese), p. 101, Nankodo, Tokyo (1955).

4. Vitamin-yu Gijutsu Konwa Kai, Assay Methods of Vitamin A in Food Materials (Japanese) p. 21 (1953).

5. U. S. Pharmacopaeia XV, 941 (1955).

6. Little, R. W., Ind. Eng. Chem., Anl. Ed. 16, 288 (1944).

7. Sahashi, Y., Saito, F., Yoshida, M., Nakayama, A., Miyazaki, K. and Harashima, K., Vitamins 6, 589 (1953).

8. Isler, O., Linder, H., Montavan, M., Rüegg, R., and Zeller, P., Helr. Chim. Acta 39, 249 (1956).

9. Lowry, O.H., and Bessey, O.A., J. Biol. Chem. 163, 633 (1946).

10. Edisbury, J.R., Gillam, A.E., Heilbron, I. M., and Morton, R.A., Biochem. J. 26, 1164 (1932). 